\title{
The changing distribution of occupational asthma: a survey of supermarket bakery
}

\section{workers}

\author{
A. Brant*, J. Berriman*, C. Sharp\#, J. Welch*, C. Zekveld*, M. Nieuwenhuijsen ${ }^{\star}$, \\ J. Elms ${ }^{+}$, A. Newman-Taylor* and P. Cullinan*
}

ABSTRACT: In the UK, since the mid 1980s, supermarkets have accounted for an increasing volume of bread production. Occupational asthma among employees who produce bread from raw ingredients in supermarkets has not been previously investigated.

A cross-sectional survey was undertaken involving 239 (71\%) employees from 20 different supermarket bakeries. The work-related symptoms were investigated by using questionnaires and measuring the radioallergosorbent test serum-specific immunoglobulin (Ig)E to flour and fungal $\alpha$-amylase. A total of 89 employees underwent whole-shift personal measurement of dust exposure.

The geometric mean dust exposure for bakers was $1.2 \mathrm{mg} \cdot \mathrm{m}^{-3}$, which was higher than for other bakery employees. A total of $37(15 \%)$ employees also reported work-related chest symptoms. Serum IgE to flour was present in $24(11 \%)$ employees and to fungal $\alpha$-amylase in nine (4\%) employees. The combination of work-related chest symptoms and specific IgE was found in six $(9 \%)$ bakers, one (4\%) manager and two (3\%) assistants. One-quarter of all employees, but half of bakers and managers, had previously worked for different, mainly small, bakeries.

This population of bakery workers has important levels of sensitisation and work-related respiratory symptoms, despite low levels of dust exposure. Changes in the location and process of bread manufacture have led to a change in the distribution of bakers' asthma in the UK.

KEYWORDS: Amylase, bakers, flour, immunoglobulin E, occupational asthma

0 ince the mid 1980s relatively small, retail bakeries have been the fastest growing sector of the baking industry in the UK [1]. Commonly located within supermarkets, most produce bread from raw ingredients. This sector makes up nearly $20 \%$, by sales volume, of the baking industry [2], but their employees have not previously been investigated for occupational asthma.

Asthma arising from workplace exposure to cereal flour or baking enzymes (bakers' asthma) is one of the commonest causes of occupational asthma in Europe [3, 4] with, in the UK, an estimated annual incidence of 951 per million bakery workers [4]. Most investigations of the disease have been within large industrial bakery or milling settings. There are only limited studies in small or craft bakeries [5, 6]. Work-related respiratory symptoms and sensitisation to both flour and fungal $\alpha$-amylase have been related to inhalable dust or allergen concentrations [7-9], with atopy probably the most important modifier in these relationships.
Seven sentinel cases of bakers' asthma from the employees of a supermarket company were referred to the current authors' clinical service. Consequently, in cooperation with the company, a survey of their stores was undertaken to investigate the prevalence distribution and determinants of work-related chest symptoms and sensitisation in this workforce. The combination of work-related chest symptoms and specific sensitisation is an acceptable, epidemiological estimate of occupational asthma [10].

\section{METHODS \\ Subjects}

In 2001, the company had over 300 stores where bread was produced from raw ingredients. Within each supermarket bakery, four main job categories could be distinguished: baker, manager, confectioner and assistant. The tasks of a baker include the emptying of $20 \mathrm{~kg}$ bags of flour and other essential ingredients, including powdered enzymes, into mixing bowls, the dusting of loaves with flour, and the cleaning of equipment

\section{AFFILIATIONS}

*Dept of Occupational and Environmental Medicine, National Heart and Lung Institute, and

"Dept of Environmental Science and Technology, Imperial College, London,

\#WorkFit-UK, Occupational Health Consultancy, Bury St Edmunds, and ${ }^{+}$Health and Safety Laboratory, Sheffield, UK.

CORRESPONDENCE

A. Brant

Dept of Occupational and Environmental Medicine National Heart and Lung Institute Imperial College 1b Manresa Rd London SW3 6LR UK

Fax: 442073518336

E-mail: a.brant@ic.ac.uk

Received:

May 062004

Accepted after revision:

September 102004 
and the bakery. Managers perform several tasks, but are commonly themselves also bakers. Confectioners finish and decorate pastries and produce doughnuts. Bakery assistants may be packers, counter staff or bakers not involved in the mixing of raw ingredients. Batch baking starts in the early morning and the baker's shift is usually finished by midday. Confectioners often start their work shift not long after the bakers; managers and assistants have shifts that are spread throughout the opening hours of the store and may extend into the early evening.

An independent workplace cross-sectional survey of all bakery employees in 20 in-store bakeries was undertaken. All individual results were confidential. For logistical reasons, stores were selected from a limited geographical area; 25 with an in-store bakery fell within this area and 20 were randomly selected for survey. These bakeries did not differ in baking process, size or number of employees from company bakeries in the rest of the country. Due to employees' variable shift and work-hour patterns, multiple visits by the investigator (A. Brant) to each store were necessary to attain good coverage.

\section{Questionnaire}

Each employee was invited to complete a questionnaire regarding their employment history and any respiratory symptoms. They were asked to categorise their primary job role as baker, manager, confectioner or assistant, and state whether their job included performing the tasks of a baker. Information about previous jobs for the same or other employers was collected. Employees who had previous baking experience were asked to categorise this as work in supermarket, industrial or small (craft) bakeries.

Information was collected on the following respiratory symptoms for the year prior to the survey: chest tightness, difficulty in breathing, chest wheezing or whistling (chest symptoms), and running or itchiness of the nose or eyes, or sneezing (nose or eye symptoms). These symptoms were considered work-related if they improved after $\geqslant 2$ days away from work. Doctor-diagnosed asthma and hay fever were recorded. Employees were defined as smokers only if they were currently smoking.

\section{Immunological assessment}

Skin-prick tests were performed to cat dander, grass pollen and Dermatophadoides pteronyssinus (Allergopharma, Reinbek, Germany) and considered positive if they produced a mean weal diameter of $\geqslant 3 \mathrm{~mm}$. Participants with one or more positive tests were considered atopic. Wheat flour (five Canadian and English wheat flours provided by the Flour Milling Bakers' Research Association) and fungal $\alpha$-amylase (Novo Nordisk, Dagsvaerd, Denmark) were extracted in $0.1 \mathrm{M}$ ammonium hydrogen carbonate (BDH, Merck, West Drayton, UK) overnight by shaking. The extracts were dialysed against distilled deionised water for $16 \mathrm{~h}$ and freeze-dried. The level of serum specific immunoglobulin (Ig)E to both allergens were measured by radioallergosorbent assay, and considered positive if binding was $\geqslant 2 \%$.

\section{Exposure assessment}

Employees from the first 10 stores visited wore personal dust samplers to estimate whole-shift measurements of inhalable dust and fungal $\alpha$-amylase (Cassella IOM sampling head (Cassella Group Ltd, Kempton, UK) and a Millipore glass microfibre). Samplers were set at a flow rate of $2 \mathrm{~L} \cdot \mathrm{min}^{-1}$. Gravimetric analysis was undertaken using before and after sample weights of dust with a lower limit of detection of $0.01 \mathrm{mg}$. The samples were analysed by the Health and Safety Laboratories, Sheffield, UK, for fungal $\alpha$-amylase using a monoclonal enzyme-linked immunoassay [11]. Inhibition assays demonstrated that the assay was specific to fungal $\alpha$ amylase and was not affected by cereal $\alpha$-amylases, which occur naturally in flour. The lower limit of detection for fungal $\alpha$-amylase was $1 \mathrm{ng} \cdot \mathrm{mL}^{-1}$.

\section{Analysis}

Dust samples from employees in different job categories were compared using Kruskal-Wallis tests. In exposure-response analyses, job title was used as a surrogate of flour and amylase exposures. Chi-squared, Fisher's exact and Wilcoxon rank sum tests were used to examine relationships between job title and outcomes (work-related chest or eye/nose symptoms, sensitisation to flour or fungal $\alpha$-amylase, combination of symptoms and specific sensitisation). Other risk factors included age, sex, smoking, atopy and total time worked in any bakery. Risk factors that were significant on univariate analysis $(\mathrm{p}<0.05)$ were included in a logistic regression model. Clustering, or inter-store variability, was adjusted for by using robust standard errors. Effect modification was assessed by the likelihood-ratio test. Mixed-effects generalised least squares (GLS) regression was used to assess the variation of dust measurements between job title and stores.

Approval for the survey was provided by the ethics committee of Royal Brompton and Harefield Hospital NHS Trust, London, UK.

\section{RESULTS}

In total, 239 (71\%) employees from the 20 stores took part in the survey (table 1). Coverage was good for bakers (89\%), managers $(100 \%)$, and confectioners $(95 \%)$, but only modest for bakery assistants (50\%). The main reason for nonresponse was unavailability due to shift patterns, a particular difficulty with bakery assistants who often worked limited hours in the weekends or evenings. All answered the questionnaire, 233 (97\%) had a skin-prick test, and 210 (88\%) provided a blood sample.

The median age of the participants was 36 yrs (range 1867 yrs). Most bakers and managers were male. The prevalence of smoking was highest among managers. Atopy was evenly spread across all work groups. Half the confectioners and one in five assistants undertook the tasks of a baker. Managers had worked in bakeries for longer than employees in other job groups. The duration of employment in bakeries was least for assistants.

Altogether, 89 employees completed whole-shift, personal dust monitoring. Three dust sample measurements, collected from two assistants and a confectioner, were below the lower limit of detection. There was a significant relationship $(p=0.0001)$ between job title and geometric mean dust exposure. The variation of dust levels was predominantly due to within-store (i.e. job title) rather than between-store variability (mixed 
TABLE 1 Participation, demographics and personal dust measurements

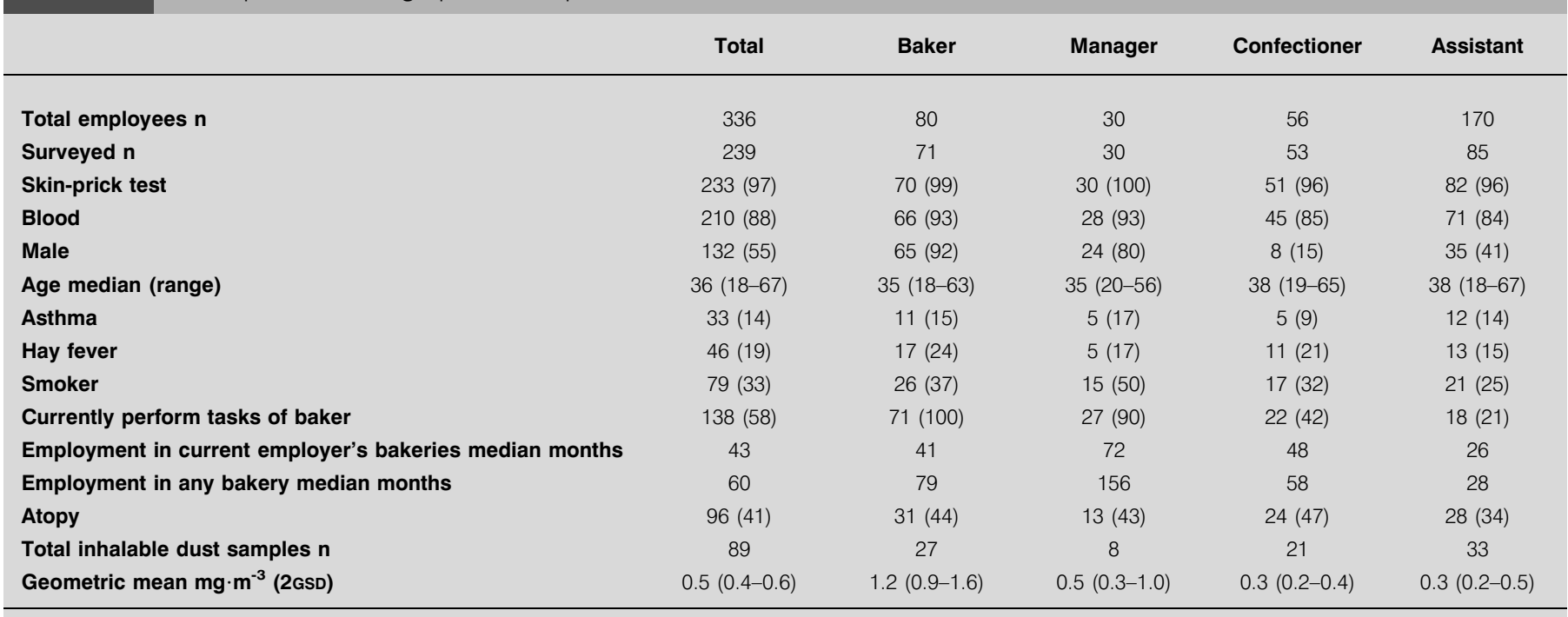

Data presented as n (\%) unless otherwise stated. GSD: geometric standard deviations.

effects GLS regression intraclass correlation: $\rho=0.04)$. Only three samples measured any fungal $\alpha$-amylase. These were collected by, a baker $\left(3.3 \mathrm{ng} \cdot \mathrm{m}^{-3}\right)$, a manager $\left(12.4 \mathrm{ng} \cdot \mathrm{m}^{-3}\right)$ and a bakery assistant $\left(3.9 \mathrm{ng} \cdot \mathrm{m}^{-3}\right)$, respectively. All reported that they sometimes performed the tasks of a baker as part of their job.

Chest and work-related chest symptoms were, respectively, reported by $34 \%$ and $15 \%$ of employees (table 2 ), and eye/nose and work-related eye/nose symptoms by $58 \%$ and $26 \%$. In total, $11 \%$ reported a combination of these work-related symptoms. The prevalence of work-related symptoms did not differ significantly between employees in different job categories (chest symptoms $p=0.48$, eye/nose symptoms $\mathrm{p}=0.18)$ or between males and females $(\mathrm{p}=0.84)$. There was no association between work-related symptoms and length of employment in a bakery $(\mathrm{p}=0.27)$

Altogether, 27 employees had raised levels of specific $\operatorname{IgE}$ antibodies to either flour or amylase antigens. Of these, 19 $(70 \%)$ were bakers (table 2$)$. Of the remaining eight, all but one reported performing the tasks of a baker as part of their job. A high proportion $(27 \%)$ of bakers were sensitised to flour. Logistic regression confirmed a significant and independent

TABLE 2 Respiratory symptoms and specific immunoglobulin (Ig)E sensitisation by job title

\begin{tabular}{|c|c|c|c|c|c|}
\hline & Total & Baker & Manager & Confectioner & Assistant \\
\hline Subjects $n$ & 239 & 71 & 30 & 53 & 85 \\
\hline Chest & $81(34)$ & $21(30)$ & $9(30)$ & $21(40)$ & $30(35)$ \\
\hline Eye/nose & $138(58)$ & $38(54)$ & $17(57)$ & $32(60)$ & $51(60)$ \\
\hline Either & $155(65)$ & $42(59)$ & $19(63)$ & $37(70)$ & $57(67)$ \\
\hline Chest & $37(15)$ & $14(20)$ & $3(10)$ & $8(15)$ & $12(14)$ \\
\hline Eye/nose & $63(26)$ & $18(25)$ & $9(30)$ & $18(34)$ & $18(21)$ \\
\hline Either & $73(31)$ & $22(31)$ & $9(30)$ & $20(38)$ & $22(26)$ \\
\hline Both & $27(11)$ & $10(14)$ & $3(10)$ & $6(11)$ & $8(9)$ \\
\hline \multicolumn{6}{|c|}{ Sensitisation to serum specific IgE (RAST) } \\
\hline $\mathrm{n}$ & 210 & 66 & 28 & 45 & 71 \\
\hline Both & $6(3)$ & $4(6)$ & $2(7)$ & 0 & 0 \\
\hline
\end{tabular}

Data presented as $\mathrm{n}(\%)$, unless otherwise stated. RAST: radioallergosorbent test. 
relationship $(\mathrm{p}=0.0003)$ between flour sensitisation and job category. In comparison with bakers, the adjusted odds ratios (ORs) for the risk of flour sensitisation among managers, confectioners and assistants were 0.21 (95\% confidence interval (CI) $0.04-1.00), 0.06(0.01-0.65)$ and $0.12(0.02-0.73)$, respectively. Of those with specific antibodies to flour, $75 \%$ were atopic. It was not possible to examine modification of the relationship between job title and flour sensitisation by atopy, since all nonatopic flour-sensitised individuals $(n=6)$ were bakers. There was no effect modification by sex. There was no relationship between flour sensitisation and duration of employment in a bakery $(p=0.71)$.

Fungal $\alpha$-amylase sensitisation was confined to bakers and managers, except for one assistant who reported performing baking tasks. Only three employees were sensitised to fungal $\alpha$-amylase alone. There was a relationship between fungal $\alpha$ amylase sensitisation and job title, but this was not statistically significant $(\mathrm{p}=0.19)$.

Of those employees who reported work-related chest symptoms, approximately a quarter were sensitised to one or more specific allergens (table 3$)$. The proportion was higher $(46 \%)$ for bakers and managers (33\%). Of the nine employees $(4 \%)$ who reported work-related chest symptoms and who also had specific IgE to either allergen, four were sensitised to flour alone, one to fungal $\alpha$-amylase alone and four to both allergens. All but one of these reported baking as a work task. There was a positive association between job title and the reporting of work-related chest symptoms with specific sensitisation $(p=0.09)$. In comparison with bakers, the estimated ORs for the risk of this outcome among managers and assistants were 0.37 (95\% CI 0.04-3.48) and 0.29 (0.09-0.97), respectively. The association was less between job category and reported work-related eye or nose symptoms in conjunction with specific $\operatorname{IgE}$ sensitisation $(\mathrm{p}=0.2)$; in comparison with bakers, the estimated OR were for managers 0.31 (95\% CI $0.03-$ 3.11), confectioners $0.19(0.02-1.90)$ and assistants $0.24(0.05-$ 1.15). In total, seven of the 11 sensitised employees who reported work-related nose/eye symptoms also reported work-related chest symptoms.

In total, $67(28 \%)$ employees had previously worked in a bakery for a different employer; bakers (46\%) and managers $(53 \%)$ were more likely to have done so than confectioners $(19 \%)$ or assistants $(9 \%)$. A total of 46 had worked at one or more small bakeries, 18 at another supermarket and 16 in an industrial bakery.

Bakers and managers who were sensitised to fungal $\alpha$-amylase were more likely to have worked in a small bakery $(50 \%)$ or any other bakery $(75 \%)$ than those that were not sensitised ( $31 \%$ and $48 \%$, respectively; table 4 ). These differences were not statistically significant. The pattern was reversed for bakers and managers who were sensitised to flour, although the differences were small (table 4).

\section{DISCUSSION}

Among a representative sample of UK supermarket bakers, a high prevalence of work-related respiratory symptoms and specific IgE sensitisation was found. The combination, consistent with occupational asthma, was present in $9 \%$ of the bakers and $4 \%$ of all employees. These findings suggest a potentially important burden of disease in a population of bakery workers that, to the best of the current authors' knowledge, has not previously been investigated.

The overall prevalence of wheat flour and $\alpha$-amylase sensitisation were similar to those measured in surveys of employees in larger bakeries [12-14]. However, it is likely that the tasks and dust exposures of employees who work in supermarket instore bakeries are more like those of craft bakery employees; indeed, the higher frequency of flour sensitisation found among bakers $(27 \%)$ is very close to that reported $(24 \%)$ in a study of small craft bakeries in Scotland [6]. In contrast, DE Zотті et al. [5] found that in small Italian bakeries the prevalence of sensitisation was somewhat lower at $12 \%$, although different exposure groupings were not identified [5]. About a quarter of all employees in the current study

TABLE 3 Work-related respiratory symptoms and serum specific immunoglobulin (Ig)E by job title

\begin{tabular}{|c|c|c|c|c|c|}
\hline Subjects $\mathrm{n}$ & 210 & 66 & 28 & 45 & 71 \\
\hline + Flour lgE & $8(4)$ & $6(9)$ & $1(4)$ & 0 & $1(1)$ \\
\hline+ Amylase IgE & $5(2)$ & $3(5)$ & $1(4)$ & 0 & $1(1)$ \\
\hline + Flour or amylase IgE & $9(4)$ & $6(9)$ & $1(4)$ & 0 & $2(3)$ \\
\hline+ Amylase lg $\mathrm{E}$ & $6(3)$ & $4(6)$ & $1(4)$ & 0 & $1(1)$ \\
\hline + Flour or amylase lgE & $11(5)$ & $7(11)$ & $1(4)$ & $1(2)$ & $2(3)$ \\
\hline Both work-related chest and eye/nose symptoms & 24 & 9 & 3 & 4 & 8 \\
\hline+ Flour lgE & $6(3)$ & $4(6)$ & $1(4)$ & 0 & $1(1)$ \\
\hline+ Amylase IgE & $5(2)$ & $3(5)$ & $1(4)$ & 0 & $1(1)$ \\
\hline
\end{tabular}

Data are presented as $n(\%)$, unless otherwise stated. 
TABLE 4 Previous bakery employment and specific immunoglobulin (Ig)E sensitisation among bakers and managers

\begin{tabular}{|c|c|c|c|c|c|c|c|c|c|}
\hline \multirow[t]{2}{*}{ Previous bakery } & \multicolumn{3}{|c|}{ IgE fungal $\alpha$-amylase } & \multicolumn{3}{|c|}{ IgE flour } & \multicolumn{3}{|c|}{ IgE either allergen } \\
\hline & + & - & $\mathrm{p}$-value & + & - & $p$-value & + & - & p-value \\
\hline Small & $4(50)$ & $27(31)$ & 0.43 & $4(20)$ & $27(36)$ & 0.16 & $5(23)$ & $26(36)$ & 0.24 \\
\hline Any & $6(75)$ & $41(48)$ & 0.27 & $8(40)$ & 39 (53) & 0.31 & $10(45)$ & $37(51)$ & 0.63 \\
\hline
\end{tabular}

reported work-related eye or nose symptoms and 15\% workrelated chest symptoms, proportions again consistent with other surveys of bakery workers [6, 9, 12, 14]. Both workrelated and other respiratory symptoms were evenly distributed across the job groups. Approximately a fifth of those with work-related respiratory symptoms were sensitised to one or more allergens, again consistent with other investigators' findings [6, 14]; this proportion was higher among bakers. Symptoms alone, work-related or otherwise, seem to be of limited but variable discriminatory power in evaluating the potential for occupational allergic disease in this setting.

The measured levels of total inhalable dust levels were low, i.e. $0.5 \mathrm{mg} \cdot \mathrm{m}^{-3}$ (2GSD: 0.4-0.6), although similar to levels reported in another study in small bakeries [15].The dust levels differed significantly between job categories, as elsewhere [16, 17]. In only three of the 89 personal samples was fungal $\alpha$-amylase detectable. The apparent discrepancy between these levels and the higher frequencies of specific sensitisation may be explained by the difficulty of capturing relevant sensitising exposures even in whole-shift, personal measurements. Previous studies, including those in small bakeries, have shown that measurements for inhalable fungal $\alpha$-amylase are commonly below the level of detection $[7,9,15]$. The current study did not measure flour allergen directly, which may have led to some exposure misclassification. On the whole, levels of flour allergen and inhalable dust in bakeries correlate closely, although the relationship depends on the use of other ingredients besides wheat flour, particularly sugar [16]. Alternatively, the levels measured may not have been representative of past dust levels when sensitisation occurred, a common problem with cross-sectional study designs. Nonetheless, the current authors were able to detect, in this way, crude exposure-response relationships for flour and amylase sensitisation, the first statistically significant. The current authors have no reason to believe that there have been important reductions in dust levels in these stores in recent times, or that these 10 stores differed importantly in their exposures from the rest of the company's stores. The variability in dust levels could be explained by job title rather than by differences between the surveyed stores. Within the population in the current study, sensitisation may reflect exposures encountered prior to work for the supermarket, a difficult issue with crosssectional study designs. Bakers and managers who were sensitised to amylase (but not flour) were more likely to have worked in another bakery, but the difference was not statistically significant. Altogether, 16 of the 27 sensitised individuals had never worked in another bakery.
A substantial majority of employees in the baking industry work in enterprises of $<20$ people [18], a group that is traditionally difficult to investigate. Studies in small bakeries are limited, but have reported relatively high levels of symptoms and sensitisation [5, 6]. Over the last $20 \mathrm{yrs}$, supermarket bakeries in the UK have steadily increased their market share of bread production from 3\% by volume in 1984 to $15 \%$ in 1999 [1, 19]. This change has paralleled the broader dominance of the supermarkets in the food retail sector and has been largely at the expense of small craft bakeries. Over the same period, the market share of craft bakeries fell from $27 \%$ to just $4 \%$. In effect, fresh bread traditionally produced by small bakeries has been increasingly manufactured in supermarkets. Footprints of this change are seen in the work histories of the study population of the current study whereby half of the bakers and managers had previously worked in another, usually small, bakery. It is interesting to speculate that, rather than uncovering a new source of bakers' asthma, the current authors' clinical experience and subsequent survey has simply revealed a transfer of disease burden from one business sector to another. Supermarket bakeries are likely to have a higher level of occupational health surveillance than traditional craft bakeries, and employees with work-related disease may become more visible when they become part of a larger organisation. Greater awareness of business dynamics, changes in the site of production and, therefore, the distribution of disease may be useful in future proactive prevention strategies in occupational asthma.

\section{ACKNOWLEDGEMENTS}

The authors would like to thank A. Curran and E. Robinson, Health and Safety Laboratory, Sheffield, UK, for their advice and assistance.

\section{REFERENCES}

1 Bread Bakers: 1999 Market report. Howitt S, ed. 1999.

2 Bread - UK. Mintel International Group Limited. February 2003.

3 Ameille J, Pauli G, Calastreng-Crinquand A, et al. Reported incidence of occupational asthma in France, 1996-99: the ONAP programme. Occup Environ Med 2003; 60: 136-141.

4 McDonald JC, Keynes HL, Meredith SK. Reported incidence of occupational asthma in the United Kingdom, 1989-97. Occup Environ Med 2000; 57: 823-829.

5 De Zotti R, Larese F, Bovenzi M, Negro C, Molinari S. Allergic airway disease in Italian bakers and pastry makers. Occup Environ Med 1994; 51: 548-552. 
6 Jeffrey P, Griffin P, Gibson M, Curran AD. Small bakeries: a cross-sectional study of respiratory symptoms, sensitization and dust exposure. Occup Med (Lond) 1999; 49: 237-241.

7 Nieuwenhuijsen MJ, Heederik D, Doekes G, Venables KM, Newman Taylor AJ. Exposure-response relations of alphaamylase sensitisation in British bakeries and flour mills. Occup Environ Med 1999; 56: 197-201.

8 Cullinan P, Cook A, Nieuwenhuijsen MJ, et al. Allergen and dust exposure as determinants of work-related symptoms and sensitization in a cohort of flour-exposed workers; a case-control analysis. Ann Occup Hyg 2001; 45: 97-103.

9 Houba R, Heederik DJ, Doekes G, van Run PE. Exposuresensitization relationship for alpha-amylase allergens in the baking industry. Am J Respir Crit Care Med 1996; 154: 130-136.

10 Cullinan P, Harris JM, Newman Taylor AJ, et al. An outbreak of asthma in a modern detergent factory. Lancet 2000; 356: 1899-1900.

11 Elms J, Denniss S, Smith M, et al. Development and validation of a monoclonal based immunoassay for the measurement of fungal alpha-amylase: focus on peak exposures. Ann Occup Hyg 2001; 45: 89-95.

12 Cullinan P, Lowson D, Nieuwenhuijsen MJ, et al. Work related symptoms, sensitisation, and estimated exposure in workers not previously exposed to flour. Occup Environ Med 1994; 51: 579-583.

13 Droste J, Myny K, Van Sprundel M, et al. Allergic sensitization, symptoms, and lung function among bakery workers as compared with a nonexposed work population. J Occup Environ Med 2003; 45: 648-655.

14 Houba R, Heederik D, Doekes G. Wheat sensitization and work-related symptoms in the baking industry are preventable. An epidemiologic study. Am J Respir Crit Care Med 1998; 158: 1499-1503.

15 Bulat P, Myny K, Braeckman L, et al. Exposure to inhalable dust, wheat flour and alpha-amylase allergens in industrial and traditional bakeries. Ann Occup Hyg 2004; 48: 5763.

16 Nieuwenhuijsen MJ, Sandiford CP, Lowson D, et al. Dust and flour aeroallergen exposure in flour mills and bakeries. Occup Environ Med 1994; 51: 584-588.

17 Houba R, Van Run P, Heederik D, Doekes G. Wheat antigen exposure assessment for epidemiological studies in bakeries using personal dust sampling and inhibition ELISA. Clin Exp Allergy 1996; 26: 154-163.

18 PA1003 Commerce, Energy and Industry: size analysis of United Kingdom Businesses, data for 2003. Office for National Statistics. June 2003.

19 Bread Bakers: Market report. 1995. 